\title{
Ecos filosóficos: o personagem conceitual de Sérgio Sant'Anna
}

\author{
Erica Gaião*
}

Tomando como referência o conto "A aula”, de Sérgio Sant'Anna, o presente estudo propõe uma análise das perspectivas filosóficas apresentadas pelo protagonista no decorrer do texto. Para a reflexão proposta, serão destacados aspectos relevantes que permitam caracterizar, a partir das questões apresentadas na obra O que é a filosofia? (2010), de Gilles Deleuze e Félix Guattari, o protagonista do conto como o personagem conceitual que dá voz aos temas filosóficos evocados, intencionalmente ou não, por Sant'Anna, que reverberam questões fundamentais abordadas pela filosofia ocidental desde a sua origem.

À filosofia cabe objetivamente solucionar problemas de diversas ordens e encontrar respostas, mas é sobretudo a partir das perguntas que o fazer filosófico se legitima. Desse pêndulo que oscila entre as perguntas e as respostas, nascem os conceitos. Como afirmam Deleuze e Guattari, "a filosofia é a arte de formar, de inventar, de fabricar conceitos" (2010, 9). No entanto, os conceitos têm a necessidade de personagens conceituais $^{1}$ que contribuam para a legitimação de sua definição, pois não se caracterizam como meros

\footnotetext{
*Doutoranda em Literatura Brasileira na Universidade Federal do Rio de Janeiro (UFRJ).

${ }^{1}$ Termo desenvolvido por Gilles Deleuze e Félix Guattari que, em um sentido amplo, pode ser compreendido como um heterônimo do filósofo. O personagem conceitual é o sujeito de uma filosofia, assim como Zaratustra e Dioniso em Nietzsche, e Sócrates nos diálogos platônicos.
} 
corpos celestes ou formas inteiramente feitas e aleatórias, que transitam pelo espaço à espera de apropriação por parte de alguma linha filosófica. Como criações, os conceitos não são nada sem a assinatura daqueles que os criam (cf. Deleuze; Guattari: 2010).

Já a arte literária possibilita a expressão da realidade como um processo: a exteriorização das sutilezas que contornam as experiências humanas e as micropercepções que escapam à pretensa apreensão do real. Como manifestação artística, a literatura supõe uma experiência sensível envolvendo gostos, emoções e percepções que serão partilhadas com o leitor. Assim como ocorre na filosofia, a arte literária pressupõe invenção, criação e transformação do que é passível de conhecimento, ainda que seja algo intangível e abstrato. O escritor, o artista, é o "criador de uma realidade nova, que abre no mundo um horizonte mais vasto, uma possibilidade de modo nenhum fechada mas tal que, pelo contrário, a realidade, sob todas as formas, encontra-se ampliada" (Blanchot: 2011, 230).

A ampliação da realidade, a criação, a fabricação de conceitos são desdobramentos da filosofia e da literatura que estão presentes na tessitura do texto de Sérgio Sant'Anna. Nesse sentido, "A aula" torna-se um convite à reflexão acerca da realidade como acontecimento, como devir. A partir de objetos destituídos de um significado aparente, o conhecimento vai sendo construído e desvelado. As micropercepções são analisadas no conto sob o olhar de um personagem conceitual, que atua como autor e porta-voz de questões fundamentais à compreensão da existência humana. As sutilezas são potencializadas, ressignificadas e apresentadas na narrativa como fenômenos extraordinários.

Nesse contexto, o mérito da narrativa está não somente nos recursos utilizados por Sant'Anna para captar o leitor, mas também 
na forma e no conteúdo revelados em suas entrelinhas. Se é verdadeiro que há ironia velada por parte do ficcionista em relação aos temas apresentados por seu personagem conceitual, também transparecem ao leitor mais atento as influências teóricas e literárias de Sérgio Sant’Anna, na voz do paradigmático professor universitário, figura sem nome que dá vida ao conto.

Reconhecido pela crítica atual como um dos mais importantes escritores da literatura brasileira contemporânea, Sérgio Sant'Anna publicou seu primeiro livro em 1969, intitulado O sobrevivente. A respeito da obra, considera-a subjetiva e intimista demais em relação às suas produções posteriores, embora reconheça sua força dramática e intensidade, elementos que, segundo o ficcionista, são necessários à literatura para que esta consiga atingir seu maior objetivo: cativar o leitor.

Entre o primeiro livro e o último, lançado no ano de 2017, somam-se às publicações de Sant'Anna vinte obras, incluindo contos, novelas, romances, peças e poesia. Adepto das narrativas curtas e das experimentações da linguagem, para Sérgio Sant’Anna, as palavras, assim como a música, têm melodia. O recurso explorado pelo ficcionista traduz-se na experiência do texto pelo próprio texto. Tanto nos contos quanto nas novelas, Sant'Anna cria atmosferas envolventes orquestradas pela memória, pela nostalgia e pelas vivências humanas.

Sexo, morte, vida e questões relacionadas à existência são temáticas recorrentes na literatura de Sérgio Sant'Anna, classificadas pelo autor como experiências humanas muito profundas, que precisam ser elucidadas e compartilhadas através da arte. Outra influência presente em sua literatura são as obras de arte em geral, representadas em seus textos através de experimentações visuais e 
estéticas. A geração beatnik, autores como Kafka, Sartre, Simone de Beauvoir, Hemingway, Faulkner, Joyce, os movimentos culturais e as experiências artísticas vividas nos anos 1970, tudo isso foi fundamental para o desenvolvimento de sua literatura.

Em "A aula", tais influências literárias e estéticas e as temáticas recorrentes nas obras de Sant’Anna são ressaltadas, formando um arcabouço que abriga as indagações de seu protagonista, proporcionando sentido e sustentação ao texto.

\section{Considerações sobre o conto "A aula"}

"A aula" é o segundo conto que compõe as três histórias ${ }^{2}$ reunidas no livro Breve história do espírito, publicado em 1991. Nele, Sant'Anna apresenta três personagens distintos, em diferentes fases da vida, um homem de trinta e um anos, outro de quarenta e o último acima dos cinquenta anos, tecendo ideias sobre os desafios - não tão desafiadores assim - que lhes foram impostos: um exame de seleção para um emprego, uma aula inaugural e uma festa de despedida. Embora os cenários das três narrativas sejam costumeiros e os perfis, comuns, o mérito da obra está na tessitura do texto e nas perspectivas dos personagens. Verdadeiros mergulhos na alma são produzidos pelos protagonistas forjados por Sant'Anna, e o efeito estético recai sobre o leitor, que se vê diante de labirínticas reflexões filosóficas, suscitadas a partir dos questionamentos propostos nos textos, que trazem problemas metafísicos como, por exemplo, "Quem sou eu?", "Mas quem terá gerado o Ovo Cósmico, o Átomo Primeiro, gerador de tudo, inclusive de Deus?", ou, ainda, em afirmações como "Porque onde há vida, há o germe de sua destruição" e “Talvez Ele,

\footnotetext{
2 "Breve história do espírito", "A aula" e "Adeus".
} 
Deus, esteja sendo gerado, muito aos poucos, por todas as energias atuantes no Universo, inclusive aquelas que acabam de emanar de nós aqui" (Sant’Anna: 1991).

O paradigmático personagem do conto "A aula" é um professor universitário que, ao retornar do período de férias, se depara com o desafio de preparar a aula inaugural do seu curso de estética e filosofia da comunicação, tendo "em mãos apenas um ovo, e trevas, atravessadas por um feixe de luz" (Sant'Anna: 1991, 61). Segundo o narrador, como um prestidigitador, um mágico, com esse material em mãos, o professor fará emergir uma aula que possa dar aos alunos a noção exata de seu curso.

As trevas atravessadas por um feixe de luz correspondem a um encarte publicitário da marca de cigarros John Player Special, retirado de uma revista que ele guardara em seu escritório junto com outros livros e papéis acumulados durante anos.

No decorrer do texto, é possível identificar três momentos, referentes ao protagonista, que remetem o leitor à ideia de um movimento circular. No primeiro, o personagem sai de casa desmotivado; no segundo, transforma-se em outro a partir de algo extraordinário, para, imediatamente após, retornar renovado ao mesmo ponto inicial. O protagonista é apresentado como um homem melancólico, desorientado e ávido pelo silêncio. Em seguida, esse mesmo homem assume uma nova identidade, revelando-se disposto ao enfrentamento, mais entusiasmado e seguro quanto ao seu papel de professor. Ao sair de cena para retornar à sua residência, a imagem inicial do homem melancólico é substituída pelo sujeito extasiado diante da sensação de missão cumprida, leve e esvaziado do peso de sua existência. Ao final da narrativa, o que se percebe é a ocorrência de uma transmutação da personalidade do protagonista. O homem 
fraco e fragmentado assume outra identidade, transformando-se em um sujeito autoconfiante e potente. A sua aula assemelha-se a um espetáculo cênico, cujo efeito é a catarse, a purificação das emoções sentidas anteriormente. Ao final da exposição, o professor-ator retira-se da sala resolvido, retornando para casa, inteiro e renovado.

$\mathrm{Na}$ primeira cena, o protagonista observa-se no espelho do banheiro dos professores, sentindo um "princípio de vertigem, pontadas e compressão no peito" $(1991,61)$, situação em que o narrador apresenta ao leitor um personagem aflito e titubeante diante da expectativa de retornar à atividade de professor e da tarefa de improvisar a aula inaugural tendo apenas dois objetos, aparentemente destituídos de qualquer significado. Tal situação foi descrita do seguinte modo:

Examinou o rosto no espelho, os olhos avermelhados, e teve dúvidas se conseguiria dessa vez. Nesse momento da vida, se lhe perguntassem qual o seu maior desejo, responderia sem hesitação que era o de ver respeitado o seu direito elementar de permanecer em silêncio $(1991,61)$.

Nos três parágrafos que se seguem, o narrador faz um movimento inverso no percurso do personagem, usando expressões "havia pouco" e "um pouco antes, ainda", até retornar à sua casa, no momento em que o despertador toca, "arrancando-o de um mundo infinitamente mais interessante e melhor" (1991, 62). É exatamente no instante em que o professor universitário percebe ao seu lado, na cama, uma mulher, a sua ex-aluna de anos atrás, que este se situa no tempo: fim de férias, hora de voltar para o curso e dar a primeira aula para seus novos alunos. 
Descrito como um professor empírico e, por esse mesmo motivo, percebido com desconfiança pelo chefe do departamento, em um acesso de empirismo radical e absoluto, no meio do caminho entre o estacionamento e a escola, decide parar para beber uma coca-cola. Por impulso, compra um ovo fresco para ajudá-lo com as trevas. Segundo o narrador,

embora sua cabeça não estivesse batendo bem [ou talvez por isso mesmo], ele intuía que talvez se encontrasse aí o elo perdido, a chave que lhe permitiria penetrar as trevas, à procura do qual se atormentara enquanto dirigia como um zumbi de casa até a escola. E não era um ovo, literalmente, um embrião? E não era disso que precisava: um embrião que fizesse germinar a aula e o curso? (1991, 64; grifo nosso).

Destaca-se nesse trecho uma reflexão sobre o próprio fazer da profissão de professor. Por mais empírico que o personagem se apresente, por mais empírico que um professor seja, a busca pelo elo que possa unir o embrião (do ovo) às trevas (do maço de cigarros) não seria também um reflexo da razão atuando sobre a experiência? Por mais que uma aula aconteça, como propõe o conto, o acontecimento se dá por meio de uma preparação prévia, ainda que nesse momento o aluno seja confrontado com objetos aparentemente desconectados do contexto da aula.

Esse personagem inicialmente aflito e titubeante esconde-se atrás de óculos escuros e caminha para a sala de aula como alguém que segue na direção de um cadafalso. Mas, ao mascarar-se, assume uma postura sociável, conforme descreve o narrador do conto: 
Ele dirigia sorrisos aqui e ali, erguendo o polegar da mão que estava livre para colegas, alunos e funcionários, a indicar que tudo estava em cima, quando, de fato, nada estava em cima. Pois se a sua profissão se assemelhava sem dúvida à dos atores, estes levavam a suprema vantagem de conhecer previamente o texto que deveriam dizer no palco. Quanto a ele, o que possuía como ponto de partida era apenas um ovo, e trevas, atravessadas por um feixe de luz (1991, 65; grifos do autor).

Não obstante o desânimo, ao assumir essa identidade de professor-ator, o seu desejo de permanecer em silêncio é substituído pela "vontade de luta e de dar um salto no escuro" (p. 65). "Ele cedeu, então, lugar a 'um outro', o professor que abrigava dentro de si” (p. 68), e começou a aula usando a seguinte sentença: "Tomemos como princípio o caos" (p. 68). A noção de caos, de um universo desorganizado, confunde-se com a sua própria imagem inicial de alguém que carrega dentro de si a desorganização, o niilismo e a vontade de nada.

O uso metafórico do ovo como elemento gerador de vida e palavra, e que dará origem a outras tantas palavras possíveis, é o ponto de partida para a organização desse caos inicial. No entanto, o gérmen da vida é também o prenúncio da finitude. E o jogo entre o claro e o escuro, a brancura do ovo em contraste com o negro das trevas, suscita no leitor a ideia de vida e morte, início e fim. Tal afirmação pode ser compreendida a partir da reflexão do hábil professor acerca da intenção do marketing da marca de cigarros para

atingir o consumidor no mais íntimo de suas trevas, o âmago de seu inconsciente, o seu desejo de retorno à comunhão 
indivisível com o indiferenciado de onde viemos e para o qual retornaremos, o útero, enfim, no primeiro caso, ou a morte no segundo [...]. Nesse desejo de retorno ao indiferenciado, como já vimos, confundem-se morte e vida (p. 71; grifo nosso).

Posteriormente, ele completa sua analogia destacando o feixe de luz dourada do logotipo, como um elo, um cordão umbilical, entre a vida e a não vida. Para além das metáforas, o que se destaca também é a habilidade do professor de reverter o caos inicial dando vida à aula e, consequentemente, à sua própria existência. O desânimo transforma-se em prazer e alívio aliados à sensação de dever cumprido. Como um artista que domina a sua arte, o hábil e empírico professor entrega-se de corpo e alma ao papel que assumiu.

Para além do espetáculo cênico forjado por Sant'Anna, merece destaque o desenho metalinguístico presente em alguns segmentos do conto. O mais evidente se dá em torno do próprio uso da palavra OVO, que é um palíndromo. A disposição das letras dessa palavra dá forma a uma imagem semelhante ao órgão reprodutor feminino, cujo $\mathrm{V}$ o protagonista associa a uma ligação que penetra o interior da própria vida. Segundo o professor,

na palavra ovo, em nossa língua, mais do que em qualquer outra, língua ou palavra, encontra-se em sua plenitude concreta a imagem do seu referente [...] não só por conter, por duas vezes, no vão da letra $\mathrm{O}$, principalmente quando em maiúscula, a figura do ovo, como pelo fato de que, circularmente, a palavra pode ser lida de frente para trás ou de trás para diante sem qualquer perda de forma e substância, 
num acabamento fechado e perfeito, correspondendo ao próprio ovo. Podemos chamar a atenção, também, para este vértice e vórtice da letra $\mathrm{V}$, como uma abertura e ligação, um cordão umbilical, penetrando no interior deste receptáculo da própria vida (pp. 76-7; grifo do autor).

Das interessantes considerações tecidas pelo personagem-professor-ator de Sérgio Sant’Anna, ressalta-se o seu caráter performático, atribuindo ao texto doses de humor e ironia. A narrativa converte-se em imagem, sendo possível ao leitor visualizar o cenário e a atuação do protagonista. Ademais, as passagens e reflexões que permeiam o conto revelam, propositalmente ou não, as influências estéticas e estilísticas do ficcionista. Como exemplo, tem-se a menção a Finnegans wake, ${ }^{3}$ último romance de James Joyce, publicado em 1939, ou ainda a referência ao poeta Ezra Pound. ${ }^{4}$

$\mathrm{Na}$ cena final, o destaque recai sobre o desempenho do protagonista e o desfecho de sua aula-espetáculo, gerada de modo aleatório a partir do caos. A quebra do ovo e consequentemente a liberação do líquido viscoso dentro da sala é uma metáfora para que a substância contida no gérmen possa dar origem a outras novas substâncias embrionárias, representadas pelos alunos. Tal afirmação pode ser compreendida a partir das considerações extraídas do texto

\footnotetext{
${ }^{3}$ Uma das maiores obras da literatura experimental, escrita em uma linguagem composta pela fusão de palavras em inglês a outras línguas, buscando uma multiplicidade de significados. No Brasil, foi parcialmente traduzido pelos irmãos Augusto de Campos e Haroldo de Campos em Panaroma do Finnegans Wake com o título Finnicius revém. A tradução completa foi realizada por Donaldo Schüler e publicada entre 1999 e 2004 com o título inicialmente proposto pelos irmãos Campos.

${ }^{4}$ Poeta e crítico literário norte-americano. Um dos maiores representantes do movimento modernista da poesia do século XX nos Estados Unidos. Principal representante do movimento Imagismo, participou também do Vorticismo.
} 
em momentos distintos, mas que corroboram a ideia apresentada. O primeiro enunciado destaca o caráter fecundante da aula: "Porque uma aula também era um embrião que muitas vezes só iria germinar na mente de um aluno anos depois, às vezes nos momentos mais inesperados" (p. 75). Mais adiante, o protagonista enuncia a aula como um impulso gerador, que à força impõe a geração de algo novo, ao afirmar que "assim devia terminar uma aula: com um golpe seco, incisivo, para que não se diluísse e sim germinasse, posteriormente, nos espíritos" (p. 78). Em seguida, tem-se a potência criadora da aula, revelada a partir da metáfora das trevas, da luz e da arte: "Como no caso da travessia das trevas pela luz, se não era uma certeza palpável, ao menos se constituía numa hipótese de tal grandiosidade que poderia fazer de uma reles aula uma obra de arte” (p. 79). Por fim, destaca-se a força genitora da aula por meio do sacrifício, que dá origem a outro, diferente do seu embrião originário: "E concluiu satisfeito que uma aula era também, literalmente, um sacrifício, em que um professor se imolava para renascer" (p. 82).

O renascimento do professor e as reflexões suscitadas conduzem a outras perspectivas apresentadas por Gilles Deleuze. A primeira delas está no capítulo "O trágico" do livro Nietzsche e a filosofia, no qual o filósofo propõe uma análise a partir da afirmação de que jamais encontraremos o sentido de alguma coisa se não soubermos qual força se apropria dela, pois qualquer fenômeno corresponde a um signo que encontra seu sentido na força atual. Força é apropriação. De acordo com Deleuze,

um mesmo objeto, um mesmo fenômeno muda de sentido de acordo com a força que se apropria dele [...]. O sentido é então uma noção complexa: há sempre uma pluralidade 
de sentidos - uma constelação, um complexo de sucessões, mas também de coexistências - que faz da interpretação uma arte $(1976,5)$.

Assim, é possível que um mesmo objeto ou um mesmo fenômeno mude de sentido de acordo com a força que atua sobre ele. Uma aula, portanto, pode ser compreendida como uma força gerada por outra força, que é o professor, e o seu sentido desencadeia outra força, representada pela compreensão do aluno, que pode ressignificar a força inicial e interpretá-la a seu modo. Tal entendimento atribui significação ao apelo performático do professor que Sérgio Sant'Anna concebe: após organizar o caos, dá um direcionamento aos alunos através do uso metafórico do líquido viscoso que sai do ovo, que, ao germinar, poderá originar outro sentido ou significado. Afinal, de acordo com a definição de Deleuze, o personagem apresentado por Sant'Anna no conto foi movido por duas forças: a emoção e a inteligência. A emoção se deu por conta de sua atuação. Já a sua inteligência empírica o fez transformar objetos aparentemente desconexos e sem nenhuma relação entre si em instrumentos de análise e reflexão.

\section{O personagem conceitual de Sérgio Sant'Anna}

Filosofia, literatura e produção de conceitos se entrelaçam na narrativa mordaz de Sérgio Sant’Anna. No conto “A aula”, o fazer literário funde-se ao fazer filosófico por meio de um jogo cênico articulado pelo ficcionista, tendo como instrumento um personagem conceitual. Tal qual definem Deleuze e Guattari, o personagem conceitual não corresponde a uma imagem abstrata, mas constitui um arquétipo vivo e incansável, que tem no filósofo a condição de ser e existir. Segundo os autores, 
o personagem conceitual não é o representante do filósofo, é mesmo o contrário: o filósofo é somente o invólucro de seu principal personagem conceitual e de todos os outros, que são os intercessores, os verdadeiros sujeitos de sua filosofia. Os personagens conceituais são os "heterônimos" do filósofo, e o nome do filósofo, o simples pseudônimo de seus personagens. Eu não sou mais eu, mas uma aptidão do pensamento para se ver e se desenvolver através de um plano que me atravessa em vários lugares. O personagem conceitual nada tem a ver com uma personificação abstrata, um símbolo ou uma alegoria, pois ele vive, ele insiste. O filósofo é a idiossincrasia de seus personagens conceituais. E o destino do filósofo é de transformar-se em seu ou seus personagens conceituais, ao mesmo tempo que estes personagens se tornam, eles mesmos, coisa diferente do que são historicamente, mitologicamente ou comumente (o Sócrates de Platão, o Dioniso de Nietzsche, o Idiota de Cusa). O personagem conceitual é o devir ou o sujeito de uma filosofia, que vale para o filósofo, de tal modo que Cusa ou mesmo Descartes deveriam assinar "o Idiota", como Nietzsche assinou "o Anticristo" ou "Dioniso crucificado" (2010, 85; grifo nosso).

Cabe ressaltar que, sendo o personagem conceitual o sujeito de uma filosofia, ele pode aparecer na obra por si mesmo ou por alusão. E, mesmo quando não nomeado, está lá, subterrâneo ou não, devendo, portanto, ser reconstituído pelo leitor. No caso de Platão, o seu principal personagem conceitual tem um nome próprio, Sócrates, que aparece nos diálogos platônicos como um criador de conceitos. 
Já no conto de Sérgio Sant'Anna, o seu personagem não tem nome; é reconhecido apenas como o professor. Contudo, o fato de não ser nomeado não desfaz a sua força enquanto personagem conceitual.

Se é verdadeiro que os personagens conceituais operam os movimentos que descrevem o plano de imanência do autor e intervêm na própria criação de seus conceitos, conforme afirmam Deleuze e Guattari, o protagonista-professor de Sant'Anna é o sujeito de sua filosofia, e a aula, o cenário ideal para a criação de seus conceitos. Isso porque, para que haja conceito, é necessário um plano de imanência que corresponda a um solo prévio sobre o qual esse conceito se fixa. Por plano de imanência entende-se aquilo de que a filosofia necessita para se constituir enquanto filosofia, e nele conceitos e personagens conceituais coexistem e mantêm uma relação específica.

O plano de imanência de Sant'Anna foi traçado a partir do ovo e das trevas atravessadas por um feixe de luz. Como um horizonte de acontecimentos que se desdobra através desses objetos, o plano utilizado pelo personagem conceitual do ficcionista é povoado por conceitos que se abrem ao leitor e oferecem diferentes modos de interpretação de sua pretensa filosofia. Embora se desdobre em conceitos, segundo Deleuze e Guattari, o plano de imanência não é um conceito pensado previamente, mas a imagem do pensamento para que o conceito possa se orientar. Contudo, ainda segundo os filósofos, orientar-se no pensamento não implica um ponto de referência objetivo, pois, "quando salta o pensamento de Tales, é como água que o pensamento retorna. Quando o pensamento de Heráclito se faz pólemos, é o fogo que retorna sobre ele" (2010, 53). Portanto, um plano de imanência é como um corte do caos agindo como um crivo. E, ao operar um corte no caos, o plano de imanência recorre a uma criação de conceitos. Tal compreensão pode ser verificada no 
conto, no momento em que o protagonista, ao analisar o ovo que acaba de retirar de sua bolsa, associa a imagem do ovo ao embrião que dá origem à vida e, ao mesmo tempo, ao elemento que contém o germe da destruição:

Em seu interior, se encontra a origem de toda a vida, que dará lugar a cada vez mais e mais vidas, o verbo primeiro que dará lugar a mais e mais palavras [...]. E não há tanto assim a se lamentar - embora a consciência da destruição impulsione a humanidade a lutar pelo seu retardamento -, pois estamos diante de uma fatalidade. Porque onde há vida, há o germe de sua destruição $(1991,69)$.

A ressignificação da matéria ovo, dada através da voz do personagem conceitual de Sant'Anna, suscita novos conceitos, mas esses mesmos conceitos, longe de representarem algo aleatório, refletem com precisão os desdobramentos de uma intenção filosófica originada no pensamento do autor. Portanto, o professor, enquanto personagem conceitual, atua como sujeito de uma filosofia que se estrutura a partir das influências estéticas e literárias de Sant’Anna.

O mesmo movimento referencial ocorre na passagem em que o professor inicia sua aula a partir da seguinte proposição:

"Tomemos como princípio o caos", foi o que ele se ouviu dizer. "Também podemos nomeá-lo de informe ou indiferenciado. Quando se expressa ou se figura ou mesmo se torna distinta alguma entidade, são o verbo ou a luz que atravessam esse caos, estabelecem uma diferença no indiferenciado" (1991, 68; grifos do autor). 
Tal afirmação remete à ideia contida na sentença de Anaxágoras: "No começo era o caos; depois vem a inteligência, que arruma tudo". A ideia de acaso contida no ovo e nas trevas deixa de ser acaso para tornar-se algo concreto porque a inteligência articula-se à palavra, sendo esta - a palavra - o verbo inicial, a expressão, a busca pelo sentido e a interpretação que organizam o caos, dando forma ao que existe.

A arte, aqui representada pela literatura, e a filosofia recortam o caos, mas não utilizam o mesmo plano de corte. À arte cabe aquilo que Deleuze e Guattari denominam de afectos e perceptos. E à filosofia, complexões de imanência ou conceitos. Isso não significa afirmar que a arte pensa menos que a filosofia, mas que esta pensa por um modo diverso, através das impressões sensíveis. Nada impede, portanto, que as duas entidades passem frequentemente uma pela outra, num devir que as leva a ambas, numa intensidade que as codetermina (Deleuze; Guattari: 2010).

\section{Considerações finais}

A partir da leitura e da breve interpretação do conto "A aula", de Sérgio Sant'Anna, pretendeu-se esboçar um panorama conceitual acerca das perspectivas filosóficas apresentadas pelo protagonista. À luz da filosofia de Gilles Deleuze e Félix Guattari, foi possível construir um arcabouço teórico introdutório para fundamentar as impressões suscitadas pelo texto. Ressalta-se que tal empreitada corresponde a um estudo preliminar acerca das condições de possibilidade verificadas no decorrer da narrativa. Há um caminho a trilhar no sentido de comprovar as indagações desencadeadas a partir desse enlace teórico fornecido pela literatura e pela filosofia, tão bem articulado pela escrita mordaz de Sérgio Sant’Anna. 
Cabe sublinhar que a intenção deste estudo inicial não foi afirmar em suas entrelinhas que o escritor Sérgio Sant'Anna pretendeu fazer filosofia. O que se destaca é que o autor, ao usar como instrumento a ironia, mostrou, através das inúmeras proposições do protagonista, que é possível dar significado às coisas a partir da reflexão filosófica. Um ovo e a simbologia das trevas atravessadas pelo feixe de luz foram os elementos utilizados por Sant'Anna para traçar o plano de imanência de seu personagem conceitual: o professor.

O protagonista de Sant'Anna, embora não tenha nome e seja definido por um narrador onisciente, apresenta-se no texto como o personagem conceitual descrito por Deleuze e Guattari na obra $O$ que é a filosofia?. Como afirmado anteriormente, para que o conceito tome forma, é importante a presença de um personagem conceitual que contribua para sua definição, o que não significa supor que esse personagem seja o representante do filósofo/autor, mas que tem na figura do filósofo condições de existir.

A ampliação da realidade, a criação, a fabricação de conceitos, como já comentado, são desdobramentos da filosofia e da literatura que estão presentes na tessitura do texto de Sérgio Sant’Anna. Por isso, o conto "A aula" apresenta-se ao estudioso da obra de Sant'Anna como um convite à reflexão acerca da realidade como acontecimento, como devir. A partir de objetos destituídos de um significado aparente, o conhecimento vai sendo construído e as imagens, ressignificadas no pensamento do leitor. 


\section{Referências}

BLANCHOT, Maurice. O espaço literário. Tradução de Álvaro Cabral. Rio de Janeiro: Rocco, 2011.

DAMASCENO, Verônica. "Personagens conceituais e personagens estéticos em Gilles Deleuze”. Revista Trágica: Estudos de Filosofia da Imanência, v. 8, n 3, $3^{\circ}$ quadrimestre de 2015, pp. 138-51.

DELEUZE, Gilles; GUATTARI, Félix. Nietzsche e a filosofia. Tradução de Ruth Joffily e Edmundo Fernandes Dias. Rio de Janeiro: Editora Rio, 1976.

. O que éa filosofia?. Tradução de Bento Prado Júnior e Alberto Alonso Muñoz. São Paulo: Editora 34, 2010.

SANT'ANNA, Sérgio. Breve história do espírito. São Paulo: Companhia das Letras, 1991.

. "Memórias inventadas". Jornal Rascunho. Entrevista concedida ao jornalista Luiz Rebinski. Edição 198, 2012.

ZILBERMAN, Regina. Teoria da literatura I. Curitiba: IESDE, 2008. ZOURABICHVILI, François. O vocabulário de Deleuze. Rio de Janeiro: Cienti, 2004. 


\section{Resumo}

Tendo como referência o conto "A aula", de Sérgio Sant’Anna, o presente estudo propõe uma breve análise das perspectivas filosóficas apresentadas pelo protagonista. Filosofia, literatura e produção de conceitos se entrelaçam na narrativa mordaz de Sant'Anna. O fazer literário funde-se ao fazer filosófico, por meio de um jogo cênico articulado pelo ficcionista, tendo como instrumento um personagem que produz conceitos. Para a reflexão proposta, destacam-se aspectos relevantes que permitam caracterizar, a partir da filosofia de Gilles Deleuze e Félix Guattari, o personagem conceitual que dá voz aos temas filosóficos evocados, intencionalmente ou não, por Sant'Anna, que reverberam questões fundamentais abordadas pela filosofia ocidental.

Palavras-chave: Sérgio Sant'anna; Deleuze; Guattari; Literatura Brasileira; filosofia.

\section{Abstract}

Taking as reference the short story "A aula”, by Sérgio Sant'Anna, this study proposes a brief analysis of the philosophical perspectives presented by the protagonist. Philosophy, literature and the production of concepts are interwoven in Sant'Anna's scathing narrative. The literary making is fused with the philosophical making, through a scenic game articulated by the fiction writer, using as a tool a character that produces concepts. For our analytical purposes, we select relevant aspects of Gilles Deleuze's and Felix Guattari's philosophy in order to characterize the conceptual character who gives voice to the philosophical themes evoked, intentionally or not, by Sant'Anna, reverberating key issues addressed by western philosophy.

\section{Keywords: Sérgio Sant'Anna; Deleuze; Guattari; Brazilian Literature; philosophy.}

